\title{
6
}

\section{Development of Information Technology in Hong Kong education over the past decade}

\author{
Alex Fung \\ Hong Kong Baptist University \\ Kowloon Tong, Hong Kong, China \\ Tele + 8522339 5679; Fax + 85223397894 \\ E-mail: alexfung@hkbu.edu.hk
}

\begin{abstract}
In the early 1980s computer Eeucation was introduced in Hong Kong schools as a new subject in the curriculum. Almost all secondary schools now offer computer literacy to junior form students (ages 12 to 14) and computer studies to senior form students (ages 15 to 16). Computers have not been used across the curriculum nor in the area of CAL/CAI (computer-assisted learning/instruction). Hong Kong has advanced from a developmental to a popularization phase in the use of Information Technology to assist schools in administration and management. In the development phase of over a decade individual schools produced their own Computer-Assisted School Administration (CASA) software in an uncoordinated manner. Popularization began in 1993 when the Hong Kong government started a centralized approach to implement the School Administration \& Management System (SAMS) in about 1300 schools. Schools will soon be provided with access to the Internet by the government. Whether there was conscious planning for capacity building for IT in Hong Kong is a matter of doubt. A major question is whether that path is unavoidable when developing countries are building their capacity for IT in education or if there could be quantum leaps bypassing the starts and fits of earlier implementers.
\end{abstract}

\section{Keywords}

Capacity building, computer-aided instruction/learning, management, regional policy 
Hong Kong's use of IT in education is primarily technology-driven. No proactive planning has occurred nor is there an IT policy for education. The strategy of introducing computers as a teaching subject in secondary schools followed by the introduction of the School Administration and Management Systems (SAMS) territory-wide has been driven by technology and some lessons can be learned from our experience. Other countries might ask if the way Hong Kong has used IT is unavoidable when they are building their IT capacity or if a shorter means to the ends could be found. Let's begin at the beginning.

Hong Kong's use of IT in education has increased over the past ten years. Though lagging behind business organizations, IT applications and developments are moving forward at all levels of education. Four different application and development areas of IT in education are ITEM (Information Technology in Educational Management), CAL/CAI (Computer-Assisted Learning/Instruction), Computer Studies and Teacher Support Systems (TSS). The Hong Kong Government introduced Computer Studies into the secondary school curriculum in the early 1980s but only started an Information System Strategy for computerized administration and management in 1993.

Education in Hong Kong has expanded rapidly over the last decade. Compulsory education up to the age fifteen was introduced in 1978 and there are now approximately 900 primary and 400 secondary schools in the Territory. The school system is centrally controlled by the Education Department of Hong Kong. Over $90 \%$ of students who finish the compulsory stage of education continue to secondary schools or technical institutes that provide vocational training, and $18 \%$ of students have opportunities for further studies in university degree courses.

Computers have been used by the central Education Department since the 1970s for allocating school places to students at ages 6, 12, and 15. The Joint University Admission Scheme also uses computers to keep track of student admissions. The Hong Kong Examinations Authority, responsible for administering the public school leaving and advance level examinations, has had computerized administration.

Higher education institutes introduced computer science courses in the 1970s. Today IT-related departments and courses are common and popular in local universities. The Hong Kong Academic Research Network (HARNET), administered by the Joint University Computer Centre (JUCC), links the universities to share information and resources - library resources, for example. Computer courses in about thirty secondary schools began as pilot projects in 1981 . Today over $90 \%$ of secondary schools offer computer studies in their senior grades and students can take public examinations in the subject in the Hong Kong Level Examination (HKCEE). Many schools also offer computer literacy courses to their junior secondary students but there is no government supported computer education in primary schools. 
Teaching computers as a subject in secondary schools is the easiest and cheapest way to introduce the technology into an education system because it is not that difficult to put forward justifications to policy-makers to get resources but only a small percentage of the teaching force has an opportunity for staff development in IT.

Now a huge effort is required to train staff as the government is implementing the computerized School Administration \& Management System (SAMS) project across the Territory. Putting computers into secondary schools for teaching has benefited teachers as many schools develop administrative uses for their computers. The less fortunate primary school teachers do not have such an opportunity and most of them are computer illiterate, if not resistant to IT.

\section{APPLICATIONS OF INFORMATION TECHNOLOGY IN HONG KONG SCHOOLS}

\subsection{IT in educational management}

Computerized school administration is common in Hong Kong secondary schools. According to Fung's (1991) postal survey over $85 \%$ of secondary schools were using some form of computer-assisted school administration. Word processing (86\%) and student data - personal and academic data administration (85\%) were the most popular applications. The least applied area was library administration, where only $25 \%$ of schools had computerized systems. Other types of applications include teacher records $(41 \%)$, timetable construction (39\%), financial matters $(40 \%)$ and coverage for teachers on leave $(40 \%)$.

Usually each secondary schools adopted its own applications with no standardization or compatibility across different systems. No empirical data is available for primary schools' use of school administration software but use is much less than in the secondary schools.

\section{The School Administration \& Management System (SAMS) in Hong} Kong

In September 1993 the Hong Kong government initiated the use of computers in educational management on a Territory-wide basis when it adopted an Information Systems Strategy (ISS) for the Hong Kong Education Department. This is a rare case, in terms of both the scale of implementation and investment, of a government taking a central lead in the development of a school information system. About 570 million Hong Kong dollars (\$US 70 million) was budgeted to implement the ISS in the Hong Kong education system within five years.

It is planned that all schools in the public sector will be given a centrally developed SAMS package of computer hardware and software to assist in administration and management, and the schools can be tele-linked to the Education Department headquarters and the Examinations Authority for data communication. 
The SAMS package has been distributed to about 600 schools and implementation should be completed by 1998 . Design, development and implementation phases need to address issues of hardware, software, training and support (Wild and Fung, 1997). Integration and standardization with such a centralized system as SAMS, requiring sufficient built in flexibility to handle individual school characteristics and autonomy, is no easy problem to solve. Fung (1995) has said, 'It would be very wrong to assume that given the hardware and software, information technology can be implemented into educational settings with automatic success. Using information technology in educational management, ITEM, irrespective of scope or scale, is an innovative process which needs managing' (p. 37).

The government is facing problems because many secondary schools have developed their own CASA systems. Many schools say the governmentproduced CASA system is too standardized and does not meet individual school needs. At the primary school the low computer literacy level of teachers and staff in that sector presents additional problems.

\subsection{Computer-assisted instruction and learning}

A study by Gilmore (1995) reveals that teachers using computers in their teaching had increases in confidence and used IT to provide cognitive and social benefits for students. They believed that both Computer-Assisted Learning (CAL) and Computer-Assisted Instruction (CAI) are important in the learning and teaching process. Regrettably, the Education Department has no policy for CAL and this area is very much undeveloped in Hong Kong.

Lacking a government policy, the use of computers across the curriculum is virtually non-existent in Hong Kong schools. Individual teachers and students might be using imported CAI or CAL packages but, except for several CAI packages that come with textbooks produced by publishers, little CAI/CAL material is locally developed.

Perhaps the education market is too small in Hong Kong to attract commercial development of school products - a factor that developing countries must come to grips with. Recently there are small pockets of development which include a project supported by the Language Fund of the Hong Kong government to develop a CAL package for learning the Chinese language in primary school, and a collaboration between the Education Department and the Polytechnic University to produce a CD-ROM for secondary schools. A small market is also beginning to emerge with commercial production of CAL CDROMs for learning languages and mathematics.

\subsection{Teacher Support Systems (TSS)}

The concept of Teacher Support Systems (TSSs) - IT used to support teaching - is not new. About a decade ago, the Education Department of South Australia set up a trial project - NEXUS - as an electronic information service to provide information to teachers and students (Leonard, 1990). NEXUS has developed into a system of electronic mail, bulletin boards and information databases. Users of the system can now share ideas of common interests, access 
materials and obtain experts' assistance through the network. Leonard remarks that schools are even willing to pay for the telecommunication service to enhance the teaching and learning of their students.

In Hong Kong two TSS projects currently in development provide limited access to teachers from selected schools. TELENEX was started by the Teaching of English Language Education Centre of Hong Kong University in 1994 in support of English Language teaching (Tsui, 1994). CLTSS, for teachers of Chinese Language, began development in April 1995 at the SAMS T\&R Unit of the Hong Kong Baptist University. Both projects are funded by the Language Fund of the Hong Kong government. Technical operations of the two networks are similar.

CLTSS - a two-year project to develop a computer-based information system network to support the teaching of the Chinese Language in local secondary schools - is simply a computer network with a server at the support centre that can be accessed by teachers with computers and modems at their schools. The system uses IT for sharing and disseminating valuable teaching resources. The content database in the server stores Chinese Language teaching resources for secondary schools - standard reading passages, teaching plans, teaching ideas, learning tasks, and test papers. The contents are not centrally developed by language experts but collected from teachers. In just one year 80 schools have become users of the system.

\subsection{Preparing for the Internet}

With the advent of the Internet and the World Wide Web a new era begins. The Hong Kong government will provide schools with one Internet access account each this academic year. Recent studies in America suggest that there are now more than $100000 \mathrm{E}$-mail accounts in the USA on state educational networks and approximately 600000 students networked through private and grassroots initiatives (Itzkan, 1992). Expert opinion estimates that by the end of the decade, there will be 3 to 5 million networked students in the USA.

The technology for building Chinese websites is growing more mature and, given time and resources, schools across the Hong Kong territory will be able to access a CLTSS website with hypertexts and multimedia capabilities. Similar websites for different subjects will be built in the future and teacher support systems will help to improve teaching and learning in many different subjects. We hope that the dominance of websites in English around the world will soon be balanced with websites in many different languages to the benefit of all.

\subsection{Partnership with the other sectors}

Given that Hong Kong's school system is overly centralized, the government must bear responsibility for resourcing all schools in the public sector with standard equipment. Financial implications always remain the first item on the agenda in any consideration of advancing technology in education. Partnership with business and commercial organizations is occasional, not the norm. The central development and supply of the Hong Kong SAMS to all schools, for 
instance, follows a different route to that in the UK or in New Zealand. In the UK, commercially developed packages such as the School Information Management System (SIMS) are available. In New Zealand, the University of Massey took a lead in developing and supporting the Massey University School Administration Computer (MUSAC) package for schools (Nolan, Ayres and McKinnon, 1997). Both the UK and New Zealand have contributions from the business sector and from higher education institutes in software development, and support serving the education community in a more efficient and effective way than Hong Kong is currently served. This is a strategy which developing countries should not ignore in building their capacity in IT.

\section{4}

\section{CONCLUSION}

Policy-makers need to be aware of the impact of IT on society-at-large and on education in general to prepare students for the 21 st century. A vision must be developed and an integrated IT policy to support school management, teaching and learning must be implemented. National organizations such as the National Centre for Educational Technology in UK support schools and teachers in the advancement of individual IT policies. Without such support, effective capacity building for IT in Hong Kong will not reach maximum effectiveness.

An effective policy should not emphasize the provision of the latest technology but, instead, the development of the people's capacity to use IT for a wide range of educational applications. A secondary school head in Hong Kong had the foresight to put a few computers in the school office for free access by teachers in addition to computers dedicated to Computer Studies classes. The result was that most teachers became computer-literate without attending computer courses. Such a school would accept new technologies and other educational innovations more readily than the average school. Would it not also be the same when a country thinks about capacity building in IT? Well-designed policies must have a vision of the future. Without a grasp of the needs of our future citizens in the 21 st century, we have no direction for preparing teachers to educate the next generation. Besides the commonly cited basic skills of the $3 \mathrm{Rs}$, a fourth one - skill in IT - has to be added for survival and competitiveness worldwide. The Lake Oswego School District, Oregon, USA (gopher:/gopher.nrel.org:70/00/programs/technology/plans/ lakeoswego plan) plans to provide a learning environment in which the use of technology is just as natural to students as the use of a pen or pencil is to most adults. As teachers are the facilitators for preparing students, top priority should be given to teachers' staff development in IT use. Hong Kong's lack of teacher preparation leaves some, if not most, of its teachers ten years behind in technology readiness.

Countries seeking to build capacity for IT can learn lessons from many countries already using IT in education as well as from research. Bearing in mind the different contexts and cultures of different places, the Hong Kong experience can help to generate a few guiding principles: (1) a holistic IT policy in education is required that integrates the different areas of ITEM, 
CAL/CAI, TSS and the subject teaching of IT; (2) staff development is a crucial element in such a policy, not than an add-on; (3) leadership by the central education authority is needed but decentralization and flexibility in management are necessary for effective implementation; (4) partnership and collaboration with business and/or higher education institutes are cost-effective in IT project development and support.

Working Group 3.7 of the International Federation for Information Processing (IFIP) TC3 is an international group of experts in Information Technology in Educational Management (ITEM) that welcomes networking. Developing IT capacity means developing networks of relationships across countries as well as policies within countries.

\section{REFERENCES}

Fung, A.C.W. (1991) Computer-assisted school administration in Hong Kong. Journal of Research on Computing in Education, 24(1), 41-61. Fung, A.C.W. (1995) Managing Change in ITEM. Information Technology in Educational Management. Chapman \& Hall, London.

Gilmore, A.M. (1995) Turning teachers on to computers: evaluation of a teacher development program. Journal of Research on Computing in Education, 27(3), 251-269.

Itzkan, S. (1992) How big is the global classroom? Matrix News, 2(10), 1, 78.

Leonard, R. (1990) Nexus III - Telecommunications beyond the classroom, in Computers in Education: Proceedings of the Fifth World Conference on Computers in Education (eds. A. McDougall and C. Dowling) Elsevier, Amsterdam.

Nolan, C.J.P., Ayres, D.A. and McKinnon, D.H. (1997) An operational model for the implementation of computerized school information systems, in Information Technology in Educational Management for the Schools of the Future (eds. Fung, A.C.W., Visscher, A.J., Barta, B.Z. and Teather, D.C.B.), Chapman \& Hall, London.

Tsui, A. (1994) The participant structures of TeleNex - a computer network for ESL teachers. Paper presented at the International Language in Education Conference at The University of Hong Kong.

Wild, P. and Fung, A.C.W. (1997) Evaluation of ITEM for proactive development, in Information Technology in Educational Management for the Schools of the Future (eds. Fung, A.C.W., Visscher, A.J., Barta, B.Z. and Teather, D.C.B.), Chapman \& Hall, London.

Alex C.W. Fung received a B.S. in 1970 from the University of Hong Kong and Cert.Ed., Adv.Dip. Ed., M.Ed. in subsequent years from the same university. He received his $\mathrm{Ph} . \mathrm{D}$. in educational management and administration in 1992 from the London University Institute of Education. He was a secondary school principal in Hong Kong for more than twenty years before he joined the Department of Education Studies of the Hong Kong Baptist University as senior lecturer in 1994. 
He is currently an associate professor and also Director of the SAMS T\&R Unit at the Hong Kong Baptist University. 